\title{
MORADIA, PATRIMÔNIO E SOBREVIVÊNCIA: DILEMAS EXPLÍCITOS E SILENCIADOS EM CONTEXTOS DE VIOLÊNCIA DOMÉSTICA CONTRA A MULHER
}

\author{
Raquel Ludermir \\ Flávio de Souza* \\ *Universidade Federal de Pernambuco, Programa de Pós-graduação em Desenvolvimento Urbano, Recife, \\ PE, Brasil
}

\begin{abstract}
Resumo
Este artigo explora como disparidades de gênero em relação à moradia e patrimônio se constroem e se reproduzem em contextos de violência doméstica contra a mulher, apesar dos recentes avanços legais no Brasil. Por meio de uma abordagem feminista qualitativa, o artigo examina as trajetórias de moradia de mulheres antes, durante e depois de relacionamentos abusivos e em situações aparentemente não violentas no Recife. Revela como desigualdades materiais e socialmente construídas, somadas às lacunas entre leis, políticas e sua implementação, expõem mulheres a dilemas cruciais, como sair de casa para sobreviver ou tolerar violência para ter onde morar. Para além das consequências, este artigo analisa os processos por meio dos quais a violência doméstica alimenta o déficit habitacional e a maneira como a violência patrimonialtemsido invisibilizada a despeito de seureconhecimentolegal. Expõe ainda contradições nos programas habitacionais e de regularização fundiária que podem silenciar as mulheres, mesmo quando alegam empoderá-las.
\end{abstract}

Palavras-chave

Moradia; Segurança da Posse; Violência Doméstica; Violência Patrimonial; Mulher; Gênero; Recife. 


\title{
HOUSING, PROPERTY AND SURVIVAL: EXPLICIT AND SILENCED DILEMMAS AMONG WOMEN IN DOMESTIC VIOLENCE SETTINGS
}

\author{
Raquel Ludermir* \\ Flávio de Souza* \\ *Universidade Federal de Pernambuco, Programa de Pós-graduação em Desenvolvimento Urbano, Recife, \\ PE, Brazil
}

\begin{abstract}
This article explores how gender disparities in housing and property are constructed and sustained in domestic violence settings, despite recent legal progress in Brazil. Using a feminist qualitative approach to research, the article examines women's housing histories before, during and after abusive relationships, and in seemingly non-violent settings in Recife. It reveals how material and socially constructed inequalities, added to the gaps between legal and policy frameworks and their implementation, expose women to crucial dilemmas such as fleeing from home to survive, or tolerating violence in exchange for a place to live and to secure property. Beyond the impact, the article analyzes the processes through which domestic violence fuels housing deficits and inadequacy, and how patrimonial violence has been silenced, despite legal recognition. It also reveals contradictions in government housing and tenure regularization policies that can disadvantage, even when claiming to empower women.

Keywords

Housing; Security of Tenure; Domestic Violence; Patrimonial Violence; Women; Gender; Recife.
\end{abstract}




\title{
MORADIA, PATRIMÔNIO E SOBREVIVÊNCIA: DILEMAS EXPLÍCITOS E SILENCIADOS EM CONTEXTOS DE VIOLÊNCIA DOMÉSTICA CONTRA A MULHER'
}

\author{
Raquel Ludermir \\ Flávio de Souza
}

Introdução: moradia, patrimônio e violência doméstica

\begin{abstract}
Eu aguentava porque não tinha outra opção, né? As pessoas acham que é fácil sair de uma situação dessa, mas onde é que eu ia morar, sem casa, sem trabalho e com três filhos debaixo do braço? Pelo menos ali eu tinha um teto [...] Mas depois daquela noite, eu tive que sair pra evitar o pior, e hoje vivo de favor na casa dos outros, só esperando ser enxotada de novo. (Sobrevivente de violência doméstica)
\end{abstract}

A violência doméstica contra a mulher é um problema alarmante que afeta uma em cada três mulheres em todo o mundo (WHO, 2017). Fenômeno complexo, relacionado a diversos fatores de risco e enraizado em questões de gênero - relações hierárquicas entre homens e mulheres na sociedade -, geralmente é exercida por parceiro íntimo atual ou passado e por parentes, como pais, irmãos, filhos e tios (UN, 1993; SAGOT, 2000; MENEGHEL et al., 2011).

No Brasil, a violência doméstica e familiar contra a mulher foi reconhecida pela Lei Maria da Penha (Lei $n^{0}$ 11.340) como "qualquer ação ou omissão baseada no gênero que lhe cause morte, lesão, sofrimento físico, sexual ou psicológico e dano moral ou patrimonial”, praticada no âmbito da unidade doméstica, familiar ou em qualquer relação íntima de afeto (BRASIL, 2006). Essa lei inclui pelo menos dois pontos que têm relação direta com a moradia e o patrimônio:

\footnotetext{
1. $O$ presente trabalho foi realizado com o apoio das seguintes agências de fomento à pesquisa: Conselho Nacional de Desenvolvimento Científico e Tecnológico (CNPq) e Coordenação de Aperfeiçoamento de Pessoal de Nível Superior (Capes) - Código de Financiamento 001.
} 
(i) estabelece medidas protetivas de urgência, como o afastamento do agressor do lar conjugal ou do local de convivência com a ofendida (art. 22, II); e (ii) reconhece a violência patrimonial contra a mulher, que trata explicitamente de bens, valores, direitos e recursos econômicos ( $\operatorname{art} .7^{\circ}$, IV), como bens imóveis e o direito à moradia.

As interseções entre violência doméstica e moradia vêm sendo apontadas em diversos documentos. A relatora especial da Organização das Nações Unidas sobre violência doméstica chamou atenção para o fato de que a pobreza e a falta de opções de moradia desafiam as mulheres a deixarem situações de violência e de que os despejos forçados têm um impacto desproporcional e devastador sobre elas, principalmente quando cometidos por parceiros e parentes (UN-OHCHR, 2012). As conexões entre violência doméstica e moradia se manifestam de forma ainda mais evidente na população em situação de rua. Em países que dispõem de dados sobre o tema, é possível observar que a violência doméstica é, na maioria dos casos, a causa direta que leva mulheres a essa condição e que a falta de alternativa de moradia é uma das principais barreiras enfrentadas pelas mulheres ao tentar deixar um relacionamento abusivo (NRCDV, 2015).

Contudo, apesar das notórias interfaces entre violência doméstica e moradia, esse tema vem sendo negligenciado tanto na literatura como em políticas públicas. Enquanto estudos sobre moradia consideram o problema e priorizam análises com foco no momento pós-violência, ou seja, nas consequências do ato que muitas vezes resulta no despejo das sobreviventes (PONIC et al., 2011; OCAMPO et al., 2016; MACHADO et al., 2017; LIMA, 2018; HELENE, 2019), pouco se sabe sobre as circunstâncias de moradia onde a violência acontece e os processos que antecedem esses despejos. Algumas análises sobre o regime de posse da moradia onde a violência é exercida tendem a focar a propriedade privada, inclusive como um fator que poderia reduzir a violência (PANDA; AGARWAL, 2005; PETERMAN et al., 2017), desconsiderando outras formas de posse, como aluguel, concessões e ocupações informais, e dificultando uma discussão mais profunda em relação aos contextos em que o direito social e humano à moradia não está necessariamente atrelado ao direito de propriedade privada.

A negligência das políticas públicas no Brasil em relação às interfaces entre moradia e violência doméstica fica evidente ao se observar que, em todo o território nacional, existem menos de oitenta casas-abrigo para mulheres em situação de violência e risco iminente de morte, presentes em apenas 2,4\% dos municípios do país (IBGE, 2019). Alguns estados e municípios dispõem de auxílio-aluguel para mulheres em situação de violência. Contudo, o alcance dessas ações tem sido bastante limitado. Em São Paulo, por exemplo, apenas 32 sobreviventes receberam bolsa-aluguel concedida pela Secretaria Municipal de Habitação (Sehab-SP) 
no primeiro semestre de 2015, e mesmo assim o programa foi suspenso em 2016 (PAIXÃO, 2017; CHALEGRE, 2018).

O presente artigo explora, no contexto do Recife, as relações entre moradia e violência doméstica, considerando o que acontece antes, durante e depois da violência, com ênfase na segurança da posse (definida minimamente como proteção contra despejos forçados) e nos efeitos longitudinais, como acumulação de patrimônio. Por meio de uma abordagem feminista qualitativa, o estudo examina a trajetória de moradia de 56 mulheres de baixa renda, das quais 31 relataram ter sofrido violência exercida por parceiro íntimo, 13 relataram ter sofrido violência exercida por parentes, e 12 não relataram ter sofrido violência doméstica ou familiar.

As participantes foram recrutadas em uma vara especializada de violência doméstica e em três assentamentos precários, localizados na Figura 1, selecionados por ilustrarem diferentes formas de intervenção estatal em relação à moradia: (a) Morro da Conceição, um exemplo de regularização fundiária e de melhorias urbanísticas sem recortes explícitos de gênero; (b) Passarinho, ilustrando iniciativas de alocação de terrenos para mulheres; e (c) Vila Santa Luzia, com a alocação de casas-embrião para mulheres. Na vara de violência doméstica, as sobreviventes foram recrutadas aleatoriamente quando buscavam atendimento sobre casos em curso. Nos assentamentos precários, as participantes foram recrutadas pela técnica "bola de neve”, por meio da qual lideranças locais e participantes já entrevistadas indicaram outras mulheres. Os critérios de seleção das participantes consistiam em idade acima de dezoito anos e residência atual ou recente em assentamento precário. As entrevistas semiestruturadas foram conduzidas presencialmente entre 2018 e 2019.

Dados adicionais foram coletados por meio de entrevistas semiestruturadas com lideranças locais, especialistas, operadores de serviços especializados e representantes do poder público, selecionados por sua representatividade nas áreas, nos serviços e no debate sobre moradia e enfrentamento da violência, e pelo interesse em participar. A triangulação de dados permitiu aprofundar as reflexões sobre as distâncias entre os marcos legais e políticos e as experiências vividas pelas mulheres.

Os resultados apresentados neste artigo são parte de uma pesquisa de doutorado mais ampla (LUDERMIR, 2021). Partindo das formas mais explícitas de violência, a próxima seção apresenta uma visão geral das trajetórias de moradia das participantes que relataram ter sofrido violência por ação de parceiro íntimo, seguida de uma reflexão sobre as políticas públicas voltadas ao atendimento das necessidades de moradia dessas sobreviventes. Na sequência, o artigo discute uma forma de violência mais sutil e, apesar do reconhecimento legal, por vezes invisibilizada na prática: a violência patrimonial contra a mulher, evidenciada nas disputas por 
bens imóveis no âmbito de separação e partilha de herança. Os resultados apontam, ainda, desigualdades de gênero em relação à moradia e patrimônio que se manifestam em contextos aparentemente não violentos, além de contradições de programas habitacionais e de regularização fundiária que podem silenciar, mesmo quando alegam empoderar mulheres. As conclusões sugerem implicações para práticas, políticas públicas e pesquisas futuras.

A pesquisa foi aprovada pelo Comitê de Ética em Pesquisa da Universidade Federal de Pernambuco. Todos os relatos foram anonimizados para preservar a identidade das participantes.

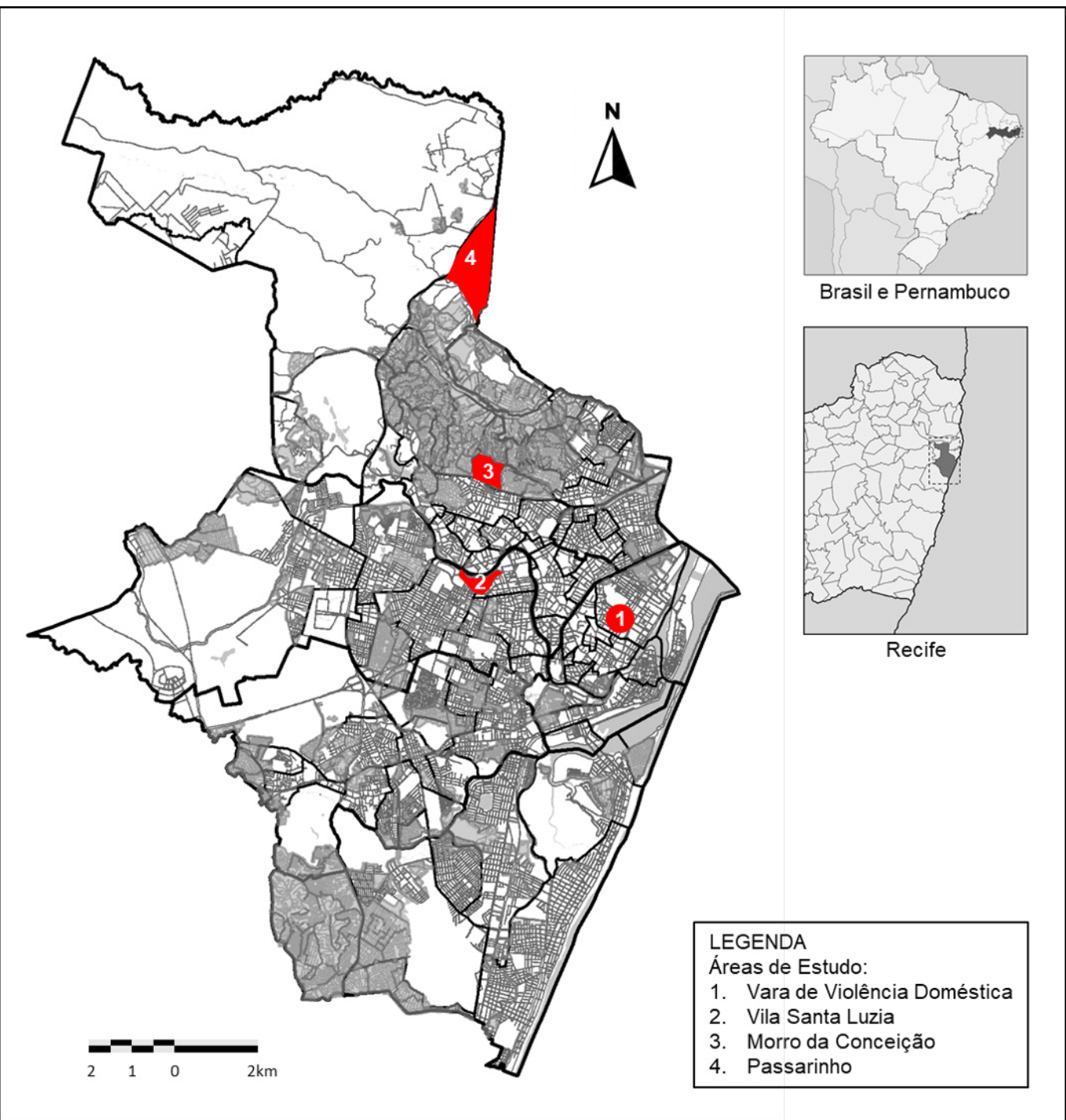

Figura 1. Localização das áreas de estudo no Recife

Fonte: Elaboração dos autores sobre base de Wikimedia Commons e Informações Geográficas do Recife (Esig), Prefeitura da Cidade do Recife, 2021. 
1. Lar doce lar? Violência exercida por parceiro íntimo e insegurança da posse da moradia para mulheres

1.1 Antes da violência

As trajetórias de moradia das participantes que sofreram violência exercida por parceiro íntimo revelam importantes disparidades materiais e de poder entre mulheres e homens no âmbito intradomicílio. O primeiro ponto que merece atenção está no fato de que algumas sobreviventes vivenciaram violência doméstica ainda na infância, contra elas ou contra a mãe, e foram forçadas a sair de casa para sobreviver, razão pela qual migraram para outras áreas ou outras cidades. Além delas, outras mulheres migraram para o Recife em busca de oportunidades, comumente encontrando abrigo e trabalho em serviços domésticos (passaram a "morar no serviço") ou em situações de moradia e emprego precárias e instáveis.

Ao formar uma união estável, uma decisão muitas vezes atrelada a uma gravidez não planejada, as mulheres entrevistadas em geral se mudaram para a casa dos parceiros ou sogros, conforme exemplificado no trecho a seguir:

A gente se conheceu perto de onde eu trabalhava, na época. [...] Quando eu descobri que tava grávida, eu ainda continuei trabalhando [como empregada doméstica] em casa de família, mas chegou uma hora que eu não aguentei mais. Eu tive que sair do trabalho, me mudei pra casa da minha sogra e ele [parceiro] ficou me sustentando enquanto eu cuidava das crianças e da casa.

Esse padrão de residência patrilinear - quando a mulher se muda para a casa do parceiro ou sogro(s) - está relacionado a uma série de fatores alimentados por discriminações e normas de gênero, tais como divisão sexual do trabalho, priorização de filhos em detrimento de filhas na antecipação de herança e distribuição de recursos no âmbito das famílias, e por disparidades de renda entre homens e mulheres. Isso resulta em desafios desproporcionais para as mulheres acessarem moradia via herança ou mercados. O relato de uma participante evidenciou como essa patrilinearidade é vivenciada na prática:

Por coincidência, eu engravidei na mesma época que a namorada do meu irmão. [...] Meu pai foi logo construindo um puxadinho pra eles, meu irmão ajudou como podia. Mas, pra mim, meu pai veio dizendo que não ia sustentar marmanjo nenhum na casa dele, que o pai do meu filho é quem tinha que me assumir. Como o pai do meu filho também não tinha onde morar, a gente foi morar na casa dos meus sogros, até a gente se ajeitar.

Quando a mulher tem acesso à moradia por intermédio do parceiro íntimo ou dos sogros, a segurança da posse da moradia dela depende, desde cedo, da 
relação com o dono da casa, e o casal passa a acumular bens conjuntos em terrenos que não pertencem à mulher. A patrilinearidade também enfraquece a percepção sobre direitos da mulher em relação à propriedade da sua família natal, conforme será detalhado adiante.

Durante a união estável, desvantagens econômicas na geração de renda, relacionadas também à divisão sexual do trabalho e a outras discriminações de gênero e interseccionais, diminuem a capacidade de as mulheres investirem renda, tempo e trabalho direto na compra, na construção ou na realização de melhorias habitacionais. A maioria das sobreviventes entrevistadas não tinha fonte de renda alguma ou recebia apenas o benefício do programa Bolsa Família. Isso inclui situações em que homens proibiram suas parceiras de trabalhar de forma remunerada, mulheres que tiveram que deixar seus empregos para cuidar da casa e dos filhos, além dos casos em que os efeitos da violência doméstica extrapolaram o domicílio e resultaram na perda do trabalho remunerado da mulher. Os efeitos dessas desvantagens econômicas no acesso à moradia e outros recursos ficam claros no depoimento abaixo:

Comprar um barraco, ajeitar uma casinha, não é fácil pra ninguém. Mas ainda é mais fácil pros homens do que pras mulheres, porque eles arranjam mais serviço, fazem uns bicos de construção [...] Pra mulher, tudo é mais difícil. A maioria das mulheres aqui não estudou porque casou cedo, teve menino cedo, aí teve que ficar em casa cuidando dos meninos porque não tem creche e não tem com quem deixar os filhos. Muitas não têm nem como ir lá fora [da comunidade] buscar alguma coisa, e quando conseguem algum trocado, mal dá pro sustento, que dirá pra juntar e comprar uma coisinha melhor.

Apesar dos desafios desproporcionais na geração de renda, algumas participantes tiveram condições de investir em melhorias habitacionais no terreno do parceiro ou dos sogros, ou de contribuir para a compra de bens com seu parceiro.

Essas desigualdades entre homens e mulheres na capacidade de gerar renda e investir de forma direta na moradia não deveriam ser um problema, haja vista que o regime de comunhão parcial de bens que rege as uniões estáveis no Brasil prevê que todos os bens adquiridos na constância do relacionamento pertencem ao casal, independentemente de quem tenha pagado por eles (BRASIL, 2002). Contudo, os relatos das participantes revelaram uma série de equívocos sobre direitos de propriedade, listados a seguir, destoantes desse marco legal:

1. "Dono é quem paga": minimiza o trabalho reprodutivo não remunerado da mulher, prejudicando aquelas que não puderam investir na moradia 
ou investiram menos que seus parceiros; é preocupante nos casos em que a mulher é dona de um terreno acessado via programa habitacional, por exemplo, e recorre ao parceiro para construir a casa;

2. "Dono do terreno é o dono da casa": minimiza a contribuição das mulheres que conseguiram investir de forma direta na moradia, e o patrimônio conjunto fica atrelado a um terreno que pertence ao parceiro ou à família dele;

3. "O que é seu é meu”: ressoa o regime de comunhão universal de bens, que só se aplica quando o casal opta por ele na formalização do relacionamento; é preocupante quando o casal mora em um bem individual da mulher, herdado por ela, por exemplo, que pode vir a ser entendido equivocadamente como bem pertencente ao casal;

4. "Não sei se é meu, mas é dos meus filhos": fala frequente nos relatos em que as mulheres não estavam plenamente cientes do seu direito à meação dos bens comuns adquiridos durante a união estável. Revela que os direitos de propriedade de herdeiros podem ser mais amplamente reconhecidos que os direitos de esposas e companheiras.

Esses equívocos sobre direitos de propriedade foram moldados caso a caso para superestimar a contribuição dos homens e minimizar a das mulheres nas estratégias de moradia e sobrevivência das famílias e tornaram-se ainda mais claros no momento da separação, conforme será detalhado adiante.

Um elemento que poderia retificar essas percepções distorcidas sobre direitos de propriedade é a documentação da posse ou propriedade dos imóveis. Contudo, com exceção das mulheres beneficiadas por programas habitacionais ou de regularização fundiária, a comprovação de posse ou propriedade dos imóveis inexistia ou estava no nome dos homens do domicílio (parceiro ou sogro das entrevistadas). Algumas mulheres não tinham nem comprovante de residência, nem guardavam seus documentos pessoais, situação bastante delicada, uma vez que, se precisarem fugir às pressas sem esses documentos, pode haver dificuldades em reivindicações futuras.

Em resumo, as sobreviventes entrevistadas geralmente não eram donas dos terrenos onde moravam, não puderam investir na construção ou na melhoria das casas ou investiram na propriedade de outras pessoas, não estavam plenamente cientes de seus direitos à propriedade conjunta e não tinham comprovação de propriedade, posse ou residência. Essas mulheres mantinham uma relação secundária com a propriedade e estavam, portanto, mais propensas a perder sua parte legítima na separação, antes mesmo de a violência acontecer. 


\subsection{Durante a violência}

Tendo em vista as disparidades de gênero em relação à moradia descritas acima, as mulheres em situação de violência por parceiro íntimo relataram ter vivenciado medo e ameaças constantes de despejo. Nos episódios de violência extrema, elas foram forçadas a deixar a residência conjugal várias vezes, retornando quando a situação se acalmava ou quando já não tinham alternativa de moradia. Essa dinâmica evidencia um estágio de despejos cíclicos, com frequência alinhada com o ciclo característico da violência doméstica, que inclui o aumento da tensão, o pico da violência e a reconciliação e "lua de mel” (SAGOT, 2000).

As mulheres saíram de casa, dentre outros fatores, por conta da escalada da violência, principalmente quando as agressões ou ameaças envolviam os filhos. $\mathrm{E}$ elas voltaram para relacionamentos abusivos em razão dos incômodos de "viver de favor na casa dos outros”, em casas superadensadas e precárias, e de não ter mais a quem recorrer. Uma das sobreviventes explicou o dilema que a manteve nesse estágio de violência e despejos cíclicos por vários anos:

Eu sabia que se eu não saísse dali ele ia terminar me matando. Mas eu já não tinha mais cara de ficar morando de favor na casa da minha irmã. Era muita gente morando naquela casa; contando comigo e meus filhos, eram três famílias, numa casa que nem banheiro tinha. [...] É muito ruim morar na casa dos outros assim, aí eu terminava voltando pra casa dele [agressor] quando as coisas se acalmavam. Eu não queria sair pra ficar na rua, eu só ia sair de novo quando tivesse um lugar certo pra ir.

Esse ciclo da violência doméstica nem sempre é entendido por familiares, amigos e vizinhos, que têm um papel fundamental na oferta de abrigo para as mulheres em situação de emergência e no estímulo para que elas busquem ajuda. Parentes e amigos das participantes muitas vezes condicionaram ajuda a julgamentos ou mecanismos de controle do comportamento das sobreviventes e, quando contrariados, recusaram ajuda, contribuindo para o isolamento das mulheres e reduzindo suas alternativas de sair da situação de violência. Além do isolamento e da falta de opções de moradia, as participantes relataram permanecer no relacionamento abusivo para evitar a perda de propriedade (marcante entre as beneficiárias de programas habitacionais) ou para garantir a herança dos filhos. Ou seja, com frequência, as sobreviventes toleraram violência doméstica em troca de um lugar para morar ou para não perder patrimônio.

Por outro lado, a maioria das participantes terminou o relacionamento abusivo saindo da residência conjugal, mesmo que isso implicasse perda patrimonial. Destacam-se três cenários: 
1. Mulheres que moravam em imóveis alugados ou dos sogros, cuja saída do lar conjugal não implicava necessariamente perda patrimonial;

2. Mulheres parcialmente proprietárias da residência conjugal - adquirida, construída ou melhorada na constância da união estável - que não estavam cientes de seus direitos de propriedade, não tinham meios nem recursos para provar e reivindicar esses direitos, ou que preferiram renunciar a eles para se verem livres da violência;

3. Mulheres total ou parcialmente proprietárias da residência conjugal com pleno conhecimento dos seus direitos de propriedade e que, justamente quando tentaram exercê-los, sofreram episódios de violência ainda mais severos, chegando à ameaça de morte ou à tentativa de feminicídio, que as levou a sair do lar conjugal para "evitar o pior".

Um dos casos mais graves foi relatado por uma sobrevivente que morava no quintal da mãe com o companheiro/agressor, em uma casa que havia sido construída pela família dela, ou seja, o agressor não tinha nenhum direito de propriedade em relação à residência conjugal. A sobrevivente tentou de diversas formas fazer com que ele deixasse a casa, até que um dia a violência foi tão severa que ela teve que sair da própria casa para sobreviver. "Eu fui parar no hospital e o médico disse que, se eu tivesse levado mais um 'chutezinho', minhas costelas iam ter perfurado meu pulmão e eu ia ter morrido lá na hora. Foi quando eu deixei tudo pra trás e fugi”, compartilhou a sobrevivente. Casos como esse ilustram como a violência doméstica pode ser utilizada como ferramenta de despejo e despossessão das mulheres, como modo de garantir que os homens mantenham o controle sobre bens e recursos.

Somente em duas exceções as mulheres conseguiram terminar um relacionamento abusivo e permanecer na casa conjugal. Isso aconteceu porque elas eram as únicas proprietárias do imóvel e conseguiram reportar o crime e acessar medida protetiva para excluir o agressor do lar. Mesmo assim, o medo de retaliação e de invasão de domicílio era notável. "Eu vivia com as janelas fechadas, pendurei as panelas atrás da porta da casa pra fazer barulho, caso ele tentasse entrar na casa", compartilhou uma das participantes sobre suas táticas de defesa.

\subsection{Depois da violência}

Encontrar um lugar para morar se mostrou um processo extremamente conturbado para as mulheres que terminaram relacionamentos abusivos. Diante das limitações das políticas habitacionais para mulheres em situação de violência, conforme será detalhado a seguir, a maioria das sobreviventes buscou abrigo na 
casa de amigos e parentes, geralmente em moradias precárias, superlotadas e compartilhadas com outras famílias, enquanto uma parcela menor das sobreviventes conseguiu alugar uma moradia, enfrentando ônus excessivo com aluguel. Esses são componentes importantes do déficit e da inadequação habitacional no país (FJP, 2021), os quais somente em 2021 passaram a ser analisados por meio de dados desagregados por gênero, comprovando as desvantagens vivenciadas pelas mulheres no tocante à moradia.

Esses novos arranjos de moradia expuseram as sobreviventes e seus filhos aos riscos de ciclos de violência de gênero novos ou recorrentes. Isso inclui mulheres que continuaram sendo assediadas por ex-parceiros quando se instalavam em lugares conhecidos, como a casa de familiares, e crianças expostas a abuso infantil em moradias superadensadas e precárias, em que se diminui a regulação da interação entre crianças e adultos. Nesse sentido, chama atenção o fato de que, como já mencionado, muitas das sobreviventes entrevistadas haviam vivenciado violência doméstica na infância, o que sugere possíveis efeitos intergeracionais de violência doméstica, acentuados pelas condições de moradia e outras desvantagens interseccionais.

\subsection{Marco legal e políticas públicas para moradia das sobreviventes}

O primeiro ponto a ser destacado em relação ao marco legal e de políticas públicas no contexto de violência doméstica é que somente $20,8 \%$ das sobreviventes no Recife quebram o silêncio e buscam ajuda (SILVA et al., 2012). A subnotificação é uma característica marcante da violência doméstica e, portanto, inúmeros casos nem sequer chegam às instâncias governamentais. Antes da denúncia, existe um longo e denso processo de reconhecer a violência, quebrar o silêncio e buscar ajuda, geralmente primeiro no âmbito das redes de apoio informais, como amigos e família (SAGOT, 2000; MENEGHEL, 2011; BARAGATTI et al., 2018).

Quanto aos casos que chegam aos serviços especializados, como delegacias de polícia, centros de referência e juizados/varas de violência doméstica, sobressai o fato de que em todo o estado de Pernambuco existem apenas quatro casas-abrigo em funcionamento, que somam cerca de 120 vagas, e que geralmente operam acima da capacidade (AMORIM, 2015; CORDEIRO, 2017; CORREIA, 2019). Essas vagas são disponibilizadas somente quando verificada a existência de risco iminente à vida ou à integridade física da mulher (PERNAMBUCO, 2009).

Não existe uma política de moradia para que mulheres saiam de situações de violência antes do risco iminente de morte. Especialistas relataram que um auxílio-aluguel no valor de $\mathrm{R} \$ 200,00$ já foi disponibilizado discricionariamente para que sobreviventes saíssem da casa-abrigo (com o objetivo de liberar vagas para outras mulheres), ou seja, ele foi concedido apenas a mulheres que já estiveram expostas 
ao risco de morte, visto que esse é um dos requisitos para ingressar no serviço de abrigamento. Foram mencionadas outras medidas, como o encaminhamento de sobreviventes para abrigos destinados à população em situação de rua ou para a casa de parentes no interior, o que gera frustração e descontentamento nas sobreviventes, influenciando sua desistência do abrigamento e o retorno a relacionamentos abusivos.

As medidas protetivas de urgência para remover o agressor do lar conjugal, previstas na Lei Maria da Penha (BRASIL, 2006), são apenas temporárias e, conforme relatado por sobreviventes e especialistas, podem gerar mais tensão e expor as mulheres à violência ainda mais severa de ex-parceiros que sabem exatamente onde elas moram, ou mesmo de familiares do ex-parceiro com quem compartilham o terreno ou a casa. Pelo menos duas das sobreviventes entrevistadas sofreram ameaças de morte e tentativas de feminicídio na vigência de medidas protetivas. Enquanto isso, as operadoras dos serviços especializados apresentavam uma perspectiva um tanto conformada, naturalizando a saída das mulheres do lar conjugal e a perda patrimonial diante da ineficácia das medidas protetivas: "Vão-se os anéis e ficam os dedos", resumiu uma delas.

A Figura 2 sintetiza os fatores determinantes das trajetórias de moradia das mulheres expostas à violência por parceiro íntimo.

\begin{tabular}{|c|c|c|}
\hline Antes & Durante & Depois \\
\hline \multirow{2}{*}{$\begin{array}{l}\text { Normas de gênero, } \\
\text { divisão sexual do trabalho }\end{array}$} & Medo e ameaças de remoção & \\
\hline & Alternativas de moradia & Romncõos normanonto \\
\hline \multirow{2}{*}{$\begin{array}{l}\text { Distorções de gênero no acesso } \\
\text { à herança e mercado imobiliário }\end{array}$} & limitadas & Remoçoes permanentes \\
\hline & Aumento da violência & Perdas materiais, perdas \\
\hline $\begin{array}{l}\text { Acesso à moradia patrilinear } \\
\text { (via companheiro) }\end{array}$ & Remoções cíclicas, reconciliação & \multirow{2}{*}{$\begin{array}{l}\text { Déficit habitacional: ônus } \\
\text { excessivo com aluguel, } \\
\text { adensamento excessivo, } \\
\text { coabitação }\end{array}$} \\
\hline $\begin{array}{l}\text { Disparidade de renda, tempo, } \\
\text { trabalho reprodutivo }\end{array}$ & $\begin{array}{l}\text { Isolamento de parentes e } \\
\text { amigos; redução das alternativas } \\
\text { de moradia }\end{array}$ & \\
\hline $\begin{array}{l}\text { Disparidades em investimentos } \\
\text { diretos na moradia }\end{array}$ & Relutância de perder patrimônio & $\begin{array}{l}\text { Novos ciclos de violência } \\
\text { de gênero, retaliação }\end{array}$ \\
\hline $\begin{array}{l}\text { Equívocos sobre direitos de } \\
\text { propriedade, meação da mulher } \\
\text { subestimada }\end{array}$ & $\begin{array}{l}\text { Barreiras no acesso à justiça; } \\
\text { medidas protetivas inefetivas }\end{array}$ & $\begin{array}{l}\text { Impacto intergeracional, } \\
\text { violência na infância (filhos }\end{array}$ \\
\hline $\begin{array}{l}\text { Informalidade da posse e } \\
\text { propriedade e união estável }\end{array}$ & $\begin{array}{l}\text { Limitações de políticas } \\
\text { habitacionais para sobreviventes }\end{array}$ & \\
\hline
\end{tabular}

Figura 2. Trajetórias de moradia das sobreviventes de violência doméstica Fonte: Elaborada pelos autores. 


\section{Violência patrimonial contra a mulher}

Este item aprofunda a análise em relação à disputa patrimonial no momento da separação e partilha da herança. O intuito é discutir em que medida esses casos constituem violência patrimonial conforme estabelecido na Lei Maria da Penha (BRASIL, 2006). Para tanto, é necessário demonstrar como os direitos de propriedade das mulheres foram violados e como essas disputas foram baseadas em gênero. Cabe ressaltar que a maioria das disputas por propriedade narradas a seguir ocorreu por meio de negociações informais no âmbito da própria família, sem a formalização nem da união estável nem da sua dissolução, tampouco da partilha de bens na separação ou herança.

\subsection{Separação}

Os processos de separação e partilha de bens relatados pelas participantes foram marcados, por um lado, por homens retendo ou subtraindo bens comuns, ora tirando proveito do desconhecimento legal das mulheres, ora adotando mecanismos para ocultar patrimônio e evitar que as mulheres reivindicassem a meação. Um exemplo claro foi relatado por uma participante cujo ex-parceiro forjou um documento de compra e venda da residência conjugal no nome do irmão para tentar dificultar qualquer pleito dela em relação à casa comprada e construída com recursos do casal durante a união estável. Por outro lado, além de as mulheres perderem sua cota legítima de propriedade quando desconheciam seus direitos ou quando não conseguiam prová-los e reivindicá-los, outras tantas renunciaram a seus direitos para fugir da crescente violência e até mesmo para escapar de estereótipos de gênero. Na voz de uma das participantes, "eles [familiares do ex-parceiro] ficavam me chamando de interesseira, até que eu decidi que não queria nada que era deles”. Casos como esse revelam uma conexão importante entre violência psicológica e patrimonial, fazendo mulheres desacreditarem e questionarem os próprios direitos.

Outras formas de violência patrimonial relatadas pelas participantes relacionavam-se à retenção ou à destruição de objetos como telefones celulares, roupas, objetos de valor sentimental, assim como de documentos civis, o que poderia dificultar que as mulheres prestassem queixa da violência sofrida ou dessem entrada em de pedidos de pensão. Documentos de propriedade também se tornavam elemento de ameaça, conforme relatou uma das participantes:

Ele rasgava minhas roupas, queria destruir tudo que via pela frente. Um dia ele partiu pra cima do documento da casa, que tava no meu nome [...] Eu tive que esconder o documento na casa do meu filho pra 
não ter o risco dele [agressor] destruir ou usar pra me ameaçar. Só depois que fui entender que aquilo era violência patrimonial.

Em alguns casos, o relato das participantes evidenciou o incômodo de seus companheiros com o fato de elas terem independência econômica e de desfrutarem de algumas vantagens, como no caso de beneficiárias de programas habitacionais que registraram os imóveis em seu nome, gerando retaliação, conforme será discutido adiante.

\subsection{Herança}

Os processos de herança também foram marcados por questões de gênero, tais como pais favorecendo filhos em detrimento de filhas na distribuição de bens inter vivos ou na antecipação de herança. 0 exemplo mais claro desse favorecimento, mencionado acima, foi o da participante que engravidou no mesmo momento que a namorada do irmão, e descreveu como o próprio pai a induziu a sair de casa para morar com os sogros, enquanto construía um "puxadinho" no terreno da família para que o irmão se tornasse "pai de família". o padrão de residência patrilinear, que apareceu como importante estratégia de moradia em contextos de recursos escassos, enfraquece as relações de facto e percebidas da mulher com o patrimônio da sua família natal.

Diante do padrão de patrilinearidade que ecoou nos relatos das participantes, não foi surpreendente identificar que, nas disputas por herança, os irmãos das participantes acreditavam ser mais "merecedores de direitos" que elas, ou alegavam ter mais capacidade de administrar os bens da família, muitas vezes aludindo à vontade implícita ou explícita dos patriarcas. As participantes relataram situações em que os irmãos pretendiam ficar com a propriedade da família, sem oferecer nenhuma compensação pelo uso exclusivo, ou vender ou empreender na propriedade, sem que elas tivessem disponibilidade de recursos ou interesse de investir na propriedade da mesma forma, processo que traz implicações legais e percebidas sobre a propriedade do imóvel.

\subsection{Dimensões de gênero das disputas patrimoniais}

As dimensões de gênero dessas disputas patrimoniais, requisito para caracterizá-las como violência patrimonial conforme previsto na Lei Maria da Penha (BRASIL, 2006), perpassam toda a trajetória de moradia das mulheres, casais e famílias. Nas disputas por imóveis entre casais, os maridos/parceiros alegam direitos de propriedade superiores aos das mulheres com base nos equívocos já mencionados - “dono é quem paga” ou "dono do terreno é dono da casa”, por exemplo -, usados de forma discricionária para minimizar a contribuição das mulheres nas 
estratégias de moradia e sobrevivência da família, desconsiderando o direito à meação delas conforme o regime de comunhão parcial de bens. Os processos que contribuem para a reprodução desses equívocos vão desde os padrões de residência patrilinear, que determinam que os casais acumulem patrimônio conjunto em terrenos não pertencentes às mulheres, até as dificuldades de a mulher investir diretamente na aquisição, construção e melhoria da moradia, em conjunção com distorções na comprovação de residência, posse ou propriedade dos imóveis.

Nas disputas por herança, geralmente envolvendo irmãos, os elementos são semelhantes. Distorções de gênero na distribuição de herança inter vivos enfraquecem as percepções sobre os direitos de propriedade das mulheres; os desafios para geração de renda enraizados em questões de gênero dificultam o investimento direto delas na propriedade da família, principalmente quando moram em outra residência, enquanto os irmãos detêm e usufruem do bem da família, ampliam seu tempo de residência e posse e controlam os documentos do imóvel.

Quando todas essas disparidades materiais e socialmente construídas entre homens e mulheres em relação ao patrimônio não foram suficientes para impedi-las de reivindicar seus direitos de propriedade, formas mais severas e tangíveis de violência doméstica - como ameaças de morte e tentativas de feminicídio - foram utilizadas como ferramenta para assegurar aos homens o controle da propriedade pertencente à mulher, ao casal ou à família.

Essas disputas por propriedade não são mera questão patrimonial: trata-se de disputas enraizadas em desigualdades de gênero, tanto material como socialmente construídas, que violam os direitos de propriedade das mulheres e que, portanto, configuram violência patrimonial.

\subsection{Marco legal e políticas públicas no enfrentamento da violência patrimonial}

Muitos casos de violência patrimonial nem sequer chegam a ser denunciados. Por vezes, as mulheres não entendem plenamente seus direitos de propriedade, nem que a violação deles configura um tipo específico de violência doméstica. As sobreviventes entrevistadas, em geral, quebraram o silêncio apenas quando outras formas de violência foram exercidas concomitantemente à violência patrimonial.

Para os casos que chegam a ser denunciados, cabe destacar que o art. 181 do Código Penal (BRASIL, 1940) isenta de pena crimes patrimoniais cometidos em prejuízo de companheira ou cônjuge, ascendente ou descendente. Uma leitura progressista desse excludente de punibilidade foi proposta por Dias (2010), com base no art. 183 do Código Penal, que prevê a não aplicação da impunidade em crime cometido com violência. Uma vez que a Lei Maria da Penha (BRASIL, 2006) define os contornos da violência patrimonial contra a mulher, não se aplicaria a impunidade 
aos crimes patrimoniais baseados em gênero cometidos por marido/parceiro, ascendente ou descendente. Contudo, servidores e especialistas apontaram que os juízes das varas de violência doméstica com frequência declinam da competência em relação à disputa por bens imóveis nesses contextos. Ou seja, os casos de violência patrimonial cometidos por homens contra suas companheiras ou esposas, mães ou filhas continuam sendo vistos como mera disputa por patrimônio a ser resolvida em varas de família, e não como violência de gênero a ser tratada nas varas especializadas de violência doméstica.

Para os casos de violência patrimonial entre irmãos e outros parentes, muitas vezes relacionados a herança, surge a dificuldade de os operadores dos serviços especializados identificar as dimensões de gênero (requisito para aplicação da Lei Maria da Penha), quando o par "agressor-vítima” não corresponde ao par "marido-mulher”. Esses casos também são entendidos como disputa patrimonial e direcionados às varas de família, o que desconsidera as inúmeras distorções e normas de gênero na antecipação e na partilha de herança, já discutidas neste artigo.

A fragmentação entre varas de família e varas de violência doméstica, além de duplicar os esforços necessários para que uma sobrevivente acompanhe processos em duas varas distintas, implica a invisibilização dos dados sobre violência patrimonial relacionada a bens imóveis nas varas de violência doméstica.

\section{Contradições de programas habitacionais e de regularização fundiária}

Apesar de esse não ser objeto central do estudo, por meio de entrevistas e análise documental foi possível problematizar uma afirmação que ecoa no campo da moradia: a de que os programas habitacionais no Brasil priorizam e empoderam as mulheres. Desde 2005, com a Lei ${ }^{0}{ }^{11.124}$, que estabelece o Sistema Nacional de Habitação de Interesse Social (SNHIS), empréstimos, escrituras públicas, contratos e registros devem ser expedidos preferencialmente no nome da mulher (BRASIL, 2005, art. 23, VI), e existem evidências empíricas de que iniciativas locais priorizaram mulheres mesmo antes de isso ser uma obrigatoriedade imposta por lei.

No entanto, a priorização da mulher nem sempre se verifica na prática. Os instrumentos para regularização fundiária disponíveis no Brasil - tais como usucapião (BRASIL, 2002), concessão de direito real de uso - CDRU (BRASIL, 1967) e concessão de uso especial para fins de moradia - CUEM (BRASIL, 2001) - são neutros em relação a gênero, permitindo a titulação no nome da mulher, do homem ou de ambos. Entrevistas com representantes de agências governamentais que implementam esses instrumentos apontam que a decisão de priorizar mulheres em ações de regularização fundiária é de natureza política: no âmbito estadual, essa priorização 
se confirma, enquanto no Recife, no âmbito municipal, os títulos são conferidos ao casal que reside nas unidades a serem regularizadas no momento da selagem.

Em ambas as situações, foram identificados elementos que podem prejudicar o acesso das mulheres à regularização fundiária. O primeiro deles é que muitas mulheres não têm documentação que comprove posse mansa e pacífica do imóvel por pelo menos cinco anos, conforme exigência legal para pleitear regularização fundiária. Recibos de compra e venda de imóveis, e mesmo contas de água e luz, em geral não aparecem no nome delas justamente pelas desvantagens econômicas já mencionadas. Operadores das políticas podem buscar outras formas de comprovar o tempo de residência delas, como matrícula dos filhos nas escolas ou registros em unidades de saúde, mas essas medidas podem gerar tensões e conflitos intradomicílio quando os homens se opõem à titulação no nome das mulheres.

Crises de masculinidade geradas pelo descontentamento dos homens com a possível inclusão ou priorização das mulheres em ações de regularização fundiária ficaram evidentes em vários relatos de operadores e especialistas. Em alguns casos, os homens não deixavam que suas companheiras falassem durante o cadastro socioeconômico para regularização fundiária feito com o casal, ou as proibiam de atender os cadastradores em visitas domiciliares quando eles não estivessem em casa, para evitar que o nome delas fosse incluído nos documentos da propriedade. Em outros casos, homens expressaram publicamente em assembleia que discordavam das medidas de priorização ou inclusão das mulheres, intimidando-as no tocante à reivindicação de seus direitos e estimulando outros homens a agir de forma semelhante.

Além disso, quando os cadastros socioeconômicos levam em conta apenas os atuais moradores do imóvel a ser regularizado, desconsiderando o histórico dos casais e famílias, pode-se legitimar a perda patrimonial de mulheres que tenham sido forçadas a deixar suas casas para escapar de relacionamentos abusivos, por exemplo, ou que tenham seguido normas de gênero aparentemente não violentas, como o padrão de residência patrilinear, enquanto os irmãos detinham a propriedade da família. Em alguns casos, mulheres que já não moravam mais no imóvel cuja regularização estava em curso conseguiram reivindicar seus direitos, e o título foi registrado no nome delas. Na sequência, elas teriam que entrar na justiça para retirar o agressor do imóvel.

Nos programas habitacionais de alocação de terrenos ou casas-embrião em que se priorizam mulheres, a principal questão diz respeito ao fato de esses programas serem dissociados de subsídios para a construção da moradia, o que leva as beneficiárias a recorrer a seus companheiros para a compra de material de construção. Foi sobretudo nesse cenário que beneficiárias de programas habitacionais 
toleraram violência para não perder seus bens. Além disso, muitas vezes a priorização das mulheres na prática é direcionada para mães-solo responsáveis pelo domicílio, desconsiderando a situação das mulheres casadas ou que vivem com companheiro (mais suscetíveis a sofrer violência doméstica).

Até que ponto a regularização fundiária ou os programas habitacionais reduzem a violência doméstica permanece uma incógnita. Por um lado, ecoaram depoimentos e impressões de que, depois dos benefícios governamentais, as mulheres conseguem superar relacionamentos abusivos em decorrência de uma mudança na correlação de poder no âmbito do domicílio. Por outro, os resultados sugerem que a violência doméstica pode não necessariamente ser menos frequente ou menos severa dentre as beneficiárias de programas habitacionais, e sim menos visível e mais silenciada em assentamentos que receberam investimentos governamentais, e por mulheres que se recusam a perder patrimônio, mesmo que isso implique tolerar atos de violência.

\section{Dilemas explícitos e silenciados. Considerações finais}

Enquanto o fim da violência doméstica soa como utopia, é urgente entender os elementos e mecanismos que dificultam as trajetórias de moradia das mulheres e acentuam discriminações e violências de gênero. As interseções entre violência doméstica, moradia e patrimônio, assim como as lacunas das leis e políticas públicas vigentes, expõem mulheres a dilemas aparentemente simples, mas com efeitos devastadores: sair de casa para sobreviver ou tolerar a violência em troca de um lugar para morar ou para não perder patrimônio. Mulheres que sofrem despejos e despossessão por meio da violência doméstica são empurradas para uma situação de déficit e inadequação habitacional que não pode ser desconsiderada nos estudos e análises sobre moradia. Por outro lado, a permanência das sobreviventes em situação de violência por falta de alternativa de moradia configura um "déficit habitacional invisível”, e isso sugere que a demanda por moradia no país é ainda maior do que as abordagens vigentes apontam.

A provisão de moradia para mulheres em situação de violência não deve se resumir aos abrigos emergenciais para sobreviventes em risco iminente de morte. São necessárias alternativas de moradia de curto, médio e longo prazo para que essas mulheres e seus filhos possam sair de relacionamentos abusivos antes que sejam expostos ao risco de morte, sem ter de voltar a esses relacionamentos em troca de um teto. A ampliação e a diversificação da provisão de moradia para mulheres devem ser consideradas parte das estratégias de prevenção e enfrentamento da violência. 
$\mathrm{O}$ acesso a programas habitacionais convencionais, mesmo quando priorizam mulheres, requer espera e recursos, inclusive humanos e políticos, por vezes indisponíveis para mulheres em situação de violência - portanto, eles não constituem uma rota concreta para saída de relacionamentos abusivos. Além disso, a ênfase na propriedade privada desses programas pode atrelar o fim da violência a perdas patrimoniais e desencorajar mulheres a terminar e denunciar relacionamentos abusivos. Outros regimes de posse, como aluguel social ou arranjos coletivos, podem ser mais compatíveis com as complexidades próprias dos ciclos da violência.

Apesar do reconhecimento legal, a violência patrimonial contra a mulher relacionada à moradia e bens imóveis permanece pouco conhecida pelas sobreviventes e invisibilizada nos serviços especializados. É importante: i) sensibilizar mulheres e homens na escala individual e das famílias em relação aos direitos de propriedade das mulheres no tocante a bens conjuntos e herança; e ii) empoderá-las legalmente, para que conheçam seus direitos e consigam identificar e reportar violência patrimonial. Também é necessário sensibilizar operadores das polícias, das varas especializadas e dos centros de referência para melhorar a forma como a violência patrimonial tem sido reportada e enfrentada, inclusive distinguindo os casos relacionados a bens imóveis daqueles envolvendo itens de menor valor econômico. Isso requer maior compreensão sobre as dimensões de gênero nas disputas patrimoniais entre irmãos, além de uma interpretação mais progressista do Código Penal, como proposto por Dias (2010), para que homens sejam punidos por crime patrimonial contra suas companheiras ou esposas, mães ou filhas.

Estudos e diagnósticos futuros sobre moradia com perspectiva de gênero devem considerar, para além do papel das mulheres nos movimentos sociais e da situação das mulheres responsáveis por domicílios, as disparidades entre homens e mulheres em domicílios nucleares e estendidos. Ou seja, deve-se levar em conta não somente a dimensão de gênero, mas também a escala individual e as dinâmicas intradomicílio e os potenciais conflitos, como a violência doméstica, que têm impacto direto na moradia. Por fim, haja vista que a violência doméstica afeta uma em cada três mulheres, é necessário entender as dimensões e os efeitos desse problema "privado" na escala das cidades, seja nas suas manifestações mais explícitas, como os despejos via violência doméstica, seja nos efeitos da violência patrimonial e do déficit habitacional hoje invisibilizados nos dados, mas vivenciados por mulheres que toleram violência para ter onde morar. 


\section{Referências}

AMORIM, E. Casa-abrigo para as mulheres em situação de violência doméstica em Pernambuco: sob a ótica das mulheres pós-abrigadas. 2015. Dissertação (Mestrado) - Universidade Federal de Pernambuco, Recife, 2015.

BARAGATTI, D. et al. Rota crítica de mulheres em situação de violência por parceiro íntimo. Revista Latino-Americana de Enfermagem, 26 (e3025), p. 1-19, 2018.

BRASIL. Decreto-lei $n^{0}$ 2.848/1940, de 7 de dezembro de 1940. Código Penal. Diário Oficial da União: Rio de Janeiro, 31 dez. 1940.

. Decreto-lei $n^{\circ}$ 271/1967, de 28 de fevereiro de 1967. Dispõe sobre loteamento urbano, responsabilidade do Ioteador concessão de uso e espaço aéreo e dá outras providências. Diário Oficial da União: Brasília, DF, 28 fev. 1967.

Medida Provisória $n^{0}$ 2.220/2001, de 4 de setembro de 2001. Dispõe sobre a concessão de uso especial de que trata o $§ 10$ do art. 183 da Constituição, cria o Conselho Nacional de Desenvolvimento Urbano - CNDU e dá outras providências. Diário Oficial da União: Brasília, DF, 5 set. 2001.

. Lei $\mathrm{n}^{0}$ 10.406/2002, de 10 de janeiro de 2002. Institui o Código Civil. Diário Oficial da União: Brasília, DF, 11 jan. 2002.

Lei $\mathrm{n}^{0}$ 11.124/2005, de 16 de junho de 2005. Dispõe sobre o Sistema Nacional de Habitação de Interesse Social - SNHIS, cria o Fundo Nacional de Habitação de Interesse Social - FNHIS e institui o Conselho Gestor do FNHIS. Diário Oficial da União: Brasília, DF, 17 jun. 2005.

Lei Maria da Penha. Lei $n^{0}$ 11.340/2006, de 7 de agosto de 2006. Cria mecanismos para coibir a violência doméstica e familiar contra a mulher, nos termos do $\S 8^{\circ}$ do art. 226 da Constituição Federal, da Convenção sobre a Eliminação de Todas as Formas de Discriminação contra as Mulheres e da Convenção Interamericana para Prevenir, Punir e Erradicar a Violência contra a Mulher; dispõe sobre a criação dos Juizados de Violência Doméstica e Familiar contra a Mulher; altera o Código de Processo Penal, o Código Penal e a Lei de Execução Penal; e dá outras providências. Diário Oficial da União: Brasília, DF, 8 ago. 2006.

CHALEGRE, V. A garantia do direito à moradia adequada na perspectiva de gênero: o combate à discriminação contra a mulher por meio das políticas públicas habitacionais. Cadernos da Defensoria Pública do Estado de São Paulo, ano 3, v. 3, n. 9, 2018.

CORDEIRO, N. Ação governamental e direitos das mulheres: abrigamento para mulheres ameaçadas de morte no Brasil. Revista Brasileira de Ciência Política, Brasília, DF, n. 23, p. 259-294, ago. 2017.

CORREIA, M. Como funciona e o que pode melhorar na rede de abrigos para mulheres vítimas de violência. Marco Zero Conteúdo, Recife, 25 nov. 2019.

DIAS, M. A Lei Maria da Penha na justiça: a efetividade da Lei 11.340/2006 de combate à violência. 2. ed. São Paulo: RT, 2010. 
FJP. Fundação João Pinheiro. Déficit habitacional e inadequação de moradias no Brasil: principais resultados para o período de 2016 a 2019. Belo Horizonte: FJP, 2021.

HELENE, D. Gênero e direito à cidade a partir da luta dos movimentos de moradia. Caderno Metrópole, São Paulo, v. 21, n. 46, p. 951-974, 2019.

IBGE. Instituto Brasileiro de Geografia e Estatística. Agência de Notícias. Mesmo com Lei Maria da Penha, somente 2,4\% dos municípios oferecem casas-abrigo. 25 set. 2019. Disponível em: https://agenciadenoticias.ibge.gov.br/agencia-noticias/2012-agencia-de-noticias/noticias/25518-mesmo-com-lei-maria-da-penha-somente-2-4-dos-municipios-oferecem-casas-abrigo. Acesso em: 30 nov. 2020.

LIMA, M. Direito à moradia para as mulheres sob a ótica da autonomia: trajetória das políticas públicas desde a CF/88. 2018. Dissertação (Mestrado) - Universidade de Brasília, Brasília, DF, 2018.

LUDERMIR, R. Housing for survival: insecurity of tenure, property loss and domestic violence against women in Recife. 2021. Tese (Doutorado) - Universidade Federal de Pernambuco, Recife, 2021.

MACHADO, I. et al. Lei Maria da Penha e advocacy feminista: uma discussão acerca da efetividade dos aluguéis sociais. SEMINÁRIO INTERNACIONAL FAZENDO GÊNERO, 11. 2017, Florianópolis. Anais [...], Florianópolis UFSC, 2017. Tema: Transformações, Conexões, Deslocamentos.

MENEGHEL, S. N. et al. Rotas críticas de mulheres em situação de violência: depoimentos de mulheres e operadores em Porto Alegre, Rio Grande do Sul, Brasil. Cad. Saúde Pública, v. 27 , n. 4, p. 743-752, 2011.

NRCDV. National Resource Center on Domestic Violence. Domestic violence and homelessness: Statistics. Harrisburg: National Resource Center on Domestic Violence, 2015.

OCAMPO, P. et al. Conceptualizing housing instability: experiences with material and psychological instability among women living with partner violence. Housing Studies, v. 31, n. 1, p. 1-19, 2016.

PAIXÃO, M. SP: apenas uma vítima de violência doméstica recebeu auxílio-aluguel no governo Dória. Brasil de Fato, São Paulo, 9 ago. 2017.

PANDA, P.; AGAWRAL, B. Marital violence, human development and women's property status in India. World Development, v. 33, n. 5, p. 823-850, 2005.

PERNAMBUCO. Lei $\mathrm{n}^{0}$ 13.977, de 16 de dezembro de 2009. Institui o serviço de abrigamento, atendimento e proteção às mulheres em situação de violência doméstica e familiar sob risco de morte, no âmbito do estado de Pernambuco, e dá providências correlatas. Diário Oficial do Estado, Recife, 2009.

PETERMAN, A. et al. Women's individual asset ownership and experience of intimate partner violence: evidence from 28 international surveys. American Journal of Public Health, v. 107, n. 5, p. 747-755, May 2017.

PONIC, P. et al. Leaving $\neq$ moving: Housing patterns of women who have left an abusive partner. Violence Against Women, v. 17, n. 12, p. 1576-1600, 2011. 
SAGOT, M. Ruta crítica de las mujeres afectadas por la violencia intrafamiliar en América Latina: estudios de caso de diez países. Washington, DC: Organización Panamericana de la Salud, 2000.

SILVA, R. et al. Enfrentamento da violência infligida pelo parceiro íntimo por mulheres em área urbana da região Nordeste do Brasil. Rev. Saúde Pública, v. 46, n. 6, p. 1014-1022, 2012.

UN. United Nations. Declaration on the Elimination of Violence against Women. General Assembly A/RES/48/104. Geneva: United Nations, 1993.

UN-OHCHR. United Nations Office of the High Commissioner on Human Rights. Women and the right to adequate housing. New York; Geneva: UN-OHCHR, 2012.

WHO. World Health Organization. Violence against women: key facts. Geneva: WHO, 2017. Disponível em: https://www.who.int/news-room/fact-sheets/detail/violence-against-women. Acesso em 30 nov. 2020. 


\section{Raquel Ludermir}

Doutora (2021) e mestra (2015) em Desenvolvimento Urbano, graduada em Arquitetura e Urbanismo (2010) pela Universidade Federal de Pernambuco (UFPE). Fez doutoradosanduíche na London School of Economics and Political Science (2019-2020). É autora da tese Housing for survival: insecurity of tenure, property loss and domestic violence against women in Recife (2021) e da dissertação Recife-mercadoria e direito à cidade: a operação urbana consorciada Joana Bezerra (2015). Também é de sua autoria o capítulo Brazil: Access to justice for securing housing, land and property rights of informal urban dwellers, que integra o livro Land and conflict: lessons from the field on conflict sensitive land governance and peacebuilding, organizado pela ONU-Habitat (2018). É coautora de Terra e moradia: conflitos fundiários urbanos em Pernambuco (2018) e Conflictos por suelo urbano y desalojos forzosos en América Latina y Caribe (no prelo). Tem pesquisado e atuado nas áreas do direito à cidade, moradia adequada e igualdade de gênero. Participou de diversos diálogos internacionais sobre os Objetivos do Desenvolvimento Sustentável, tendo avaliado e documentado boas práticas na América Latina, África e Ásia.

Email: ludermir.raquel@gmail.com

ORCID: 0000-0001-6457-8088

Contribuição de autoria: conceituação; curadoria de dados; análise formal; obtenção de financiamento; investigação/pesquisa; metodologia; escrita - primeira redação; escrita - revisão e edição. 


\section{Flávio de Souza}

Professor titular de Estudos Urbanos da Universidade Federal de Pernambuco (UFPE). Graduado em Arquitetura e Urbanismo pela mesma universidade (1990), com mestrado em Desenho Urbano pela Oxford Brookes University (1994), doutorado em Planejamento Urbano por essa mesma instituição (1998) e pós-doutorado em políticas públicas na University of Texas (2002), em Austin. Foi professor visitante no Instituto Teresa Lozano Long de Estudos Latino-Americanos (Lillas), também na University of Texas (2002), e na Facultad de Ciencias Sociales, Universidad de Buenos Aires (2014). É autor de vários artigos e capítulos de livros sobre favelas e outras questões urbanas, incluindo Pride and shame: the history of the slums in Recife, Brazil (2021); Recife: much to do about nothing (2017); Security of land tenure revised: the case of CRRU in Recife and Porto Alegre, Brazil (2004); Perceived security of land tenure in Recife, Brazil (2001); The future of informal settlements: lessons in the legalization of disputed urban land in Recife, Brazil (2001), e coautor de Urban land tenure in Brazil: from centralized state to market processes of housing land delivery (2013).

Email: fdesouza67@gmail.com

ORCID: 0000-0001-6119-7423

Contribuição de autoria: supervisão/orientação; escrita - revisão e edição.

Submissão: 30 de novembro de 2020.

Aprovação: 26 de julho de 2021.

Como citar: LUDERMIR, R.; SOUZA, F. A. M. Moradia, patrimônio e sobrevivência: dilemas explícitos e silenciados em contextos de violência doméstica contra a mulher. Revista brasileira de estudos urbanos e regionais. Dossiê Território, Gênero e Interseccionalidades. v. 23, E202126, 2021. DOI 10.22296/2317-1529.rbeur.202126

Artigo licenciado sob Licença Creative Commons CC BY 4.0.

https://creativecommons.org/licenses/by/4.o/deed.pt_BR 